\title{
Deficits of long-term memory in ecstasy users are related to cognitive complexity of the task
}

\author{
John Brown • Elinor McKone • Jeff Ward
}

Received: 23 February 2009 /Accepted: 21 December 2009 /Published online: 2 February 2010

(C) Springer-Verlag 2010

\begin{abstract}
Rationale Despite animal evidence that methylenedioxymethamphetamine (ecstasy) causes lasting damage in brain regions related to long-term memory, results regarding human memory performance have been variable. This variability may reflect the cognitive complexity of the memory tasks. However, previous studies have tested only a limited range of cognitive complexity. Furthermore, comparisons across different studies are made difficult by regional variations in ecstasy composition and patterns of use.

Objectives The objective of this study is to evaluate ecstasyrelated deficits in human verbal memory over a wide range of cognitive complexity using subjects drawn from a single geographical population.

Materials and methods Ecstasy users were compared to nondrug using controls on verbal tasks with low cognitive complexity (stem completion), moderate cognitive complexity (stem-cued recall and word list learning) and high cognitive complexity (California Verbal Learning Test, Verbal Paired Associates and a novel Verbal Triplet Associates test). Where significant differences were found, both groups were also compared to cannabis users.

Results More cognitively complex memory tasks were associated with clearer ecstasy-related deficits than low complexity tasks. In the most cognitively demanding task, ecstasy-related deficits remained even after multiple learning opportunities, whereas the performance of cannabis users approached that of non-drug using controls. Ecstasy users also had weaker deliberate strategy use than both non-drug and cannabis controls.
\end{abstract}

J. Brown $(\square) \cdot$ E. McKone $\cdot$ J. Ward

Department of Psychology, The Australian National University,

Building 39,

Canberra ACT 0200, Australia

e-mail: john.brown@anu.edu.au
Conclusions Results were consistent with the proposal that ecstasy-related memory deficits are more reliable on tasks with greater cognitive complexity. This could arise either because such tasks require a greater contribution from the frontal lobe or because they require greater interaction between multiple brain regions.

Keywords MDMA Ecstasy $\cdot$ Memory .

Cognitive complexity $\cdot$ Frontal lobe $\cdot$ Serotonin

\section{Introduction}

Methylenedioxymethamphetamine (MDMA) is the main psychoactive ingredient of the recreational drug "ecstasy". Controlled administration of MDMA causes lasting changes to serotonin levels and the functioning of serotonergic axons in the brains of animals, including higher primates (Green et al. 2003; Hatzidimitriou et al. 1999; Ricaurte et al. 1992; Sabol et al. 1996; Scanzello et al. 1993; Wang et al. 2004). Convergent neuroimaging evidence suggests that lasting brain damage also occurs in humans (Cowan et al. 2003; Reneman et al. 2001b, 2002).

The brain regions damaged by ecstasy include the hippocampus, frontal lobes and sensory areas (Buchert et al. 2003, 2004; Hatzidimitriou et al. 1999; McCann et al. 1998, 2005; O'Hearn et al. 1988). All of these areas have been shown to be critical to encoding and retrieval of long-term memories (Posner et al. 1988; Schott et al. 2005; Spiers et al. 2001; Thiel 2003). Here, we investigate the idea that as more of these brain regions are recruited by more cognitively complex memory tasks, the likelihood of behavioural ecstasyrelated deficits in long-term verbal memory might increase.

Theoretically, cognitive complexity of memory tasks can be ordered in accordance with task demands and the 
number of brain regions critically involved, as outlined in Table 1. Tests of implicit memory (unconscious automatic retrieval) have low cognitive complexity and do not require involvement of either the frontal lobes or the hippocampus; indeed, where these tasks require reference only to the identity rather than the meaning of an item (e.g. priming for a letter string on a word-non-word decision task), neuroimaging shows memory derived from priming only in perceptual areas of the cortex (e.g. Schacter and Buckner 1998; Schott et al. 2005). More complex tasks involve explicit memory (conscious deliberate retrieval). Simple explicit memory tasks involve recognition or recall for lists of single unrelated words. Neuropsychological and neuroimaging studies show this critically relies, in addition to perceptual areas, on the functioning of the hippocampus (e.g. Spiers et al. 2001; Thiel 2003). The frontal lobe is also known to have a role in explicit memory tasks that varies according to task demands. In particular, Savage et al. (2001) found prefrontal activation was relatively low on the free recall of a list of unrelated words, in contrast to relatively high prefrontal activation when subjects used categories to help them recall words drawn from four semantic categories. So, while frontal lobe strategic processing appears to contribute somewhat to performance on free recall of unrelated words, its role is not critical, and indeed behavioural studies argue that non-strategic rote learning typically plays a stronger role (cf. Mandler and Dean 1969).

Finally, more complex explicit memory tasks involve a stronger component of deliberate strategy use on behalf of subjects, such as deliberate semantic structuring of the stimuli or the top-down generation of meaningful associations between different stimuli. Functional neuroimaging studies show this type of processing activates language centres and specific parts of the frontal lobes, in particular, the prefrontal cortex (Posner et al. 1988; Roskies et al. 2001; Schreckenberger et al. 1998; Shaywitz et al. 1995). Thus, explicit memory tasks involving complex cognitive processing will rely critically on the successful recruitment of, and potentially interaction between, multiple brain regions known (at least in animals) to be damaged by ecstasy use. These include perceptual processing areas, the hippocampus and prefrontal cortex. Examples of complex explicit memory tasks include the California Verbal Learning Test (CVLT), in which subjects remember best by noticing the fact that the single words in that test can be grouped into four semantic categories (cf. Tulving and Pearlstone 1966), and Verbal Paired Associates, in which subjects best learn a pair such as "frog-table" by deliberately generating a sentence or visual image linking the two words (cf. Tulving 1962).

Crucially for our present proposal, there is indirect evidence to suggest that tasks with higher cognitive complexity might be more vulnerable to ecstasy-related damage than tasks with low cognitive complexity. Neuroendocrine challenge studies on rats report that the behavioural consequences of the inhibition of some types of serotonin receptors are only apparent in memory tasks when cognitive demands are high (outlined in Buhot 1997; Buhot et al. 2000). Similarly, in human functional magnetic resonance imaging (fMRI), Jacobsen et al. (2004) found that a prolongation of hippocampal activation in ecstasy users compared to controls occurred only when demands of a memory task were relatively high (three-back matching) and not when they were lower (one-back matching).

Turning to behavioural findings regarding memory in human ecstasy users, our interest in the present study is specifically in verbal learning for words (excluding working

Table 1 Long-term memory tasks ordered by cognitive complexity

\begin{tabular}{|c|c|c|c|}
\hline $\begin{array}{l}\text { Level of } \\
\text { cognitive } \\
\text { complexity }\end{array}$ & Task (key process) & Example stimuli & Critical brain areas \\
\hline \multirow[t]{4}{*}{$\begin{array}{l}\text { Low } \\
\text { (implicit memory) }\end{array}$} & $\begin{array}{l}\text { Stem completion } \\
\text { (nonconscious memory) }\end{array}$ & $\begin{array}{l}\text { Study: calorie } \\
\text { Test: cal }\end{array}$ & Perceptual areas \\
\hline & $\begin{array}{l}\text { Memory for lists of single unrelated } \\
\text { words (conscious memory relying } \\
\text { strongly on rote learning) }\end{array}$ & $\begin{array}{l}\text { Study: frog, table, apple, blue... } \\
\text { Test: free recall }\end{array}$ & $\begin{array}{l}\text { Perceptual areas, hippocampus } \\
\text { (frontal lobe relatively weak) }\end{array}$ \\
\hline & $\begin{array}{l}\text { Memory for lists of categorisable } \\
\text { words (optional strategic } \\
\text { elaborative processing) }\end{array}$ & $\begin{array}{l}\text { Study: dog, apple, shelf, cat, } \\
\text { table, pear } \\
\text { Test: free recall }\end{array}$ & $\begin{array}{l}\text { Perceptual areas, hippocampus, frontal lobes } \\
\text { (especially when engaging in optimal } \\
\text { category strategy) }\end{array}$ \\
\hline & $\begin{array}{l}\text { Verbal Paired Associates } \\
\text { (strategic elaborative } \\
\text { processing) }\end{array}$ & $\begin{array}{l}\text { Study: frog-table } \\
\text { Test: frog-? }\end{array}$ & Perceptual areas, hippocampus, frontal lobes \\
\hline $\begin{array}{l}\text { High } \\
\text { (complex explicit } \\
\text { memory) }\end{array}$ & $\begin{array}{l}\text { Verbal Triplet Associates } \\
\text { (more complex strategic } \\
\text { elaborative processing) }\end{array}$ & $\begin{array}{l}\text { Study: frog-chair-apple } \\
\text { Test: frog-?-? }\end{array}$ & Perceptual areas, hippocampus, frontal lobes \\
\hline
\end{tabular}


memory tasks). Previous studies testing verbal memory have used only a limited range of task complexity. Implicit memory has never been tested. Simple explicit memory (i.e. for single unrelated words) and Verbal Paired Associates (Wechsler 1997) are the only tasks to have received substantial investigation. Moreover, Verbal Paired Associates typically suffers ceiling effects beyond the first learning trial, and most studies have not reported this trial in isolation. The CVLT has been used twice (Halpern et al. 2004; Semple et al. 1999), but neither study reported the semantic clustering index (SCI) to provide a direct measure of the extent to which ecstasy users were implementing the ideal memory strategy of grouping recall items by semantic category.

For the verbal learning tests that have been reported, previous findings are as follows. On tests of immediate free recall of lists of single unrelated words, some studies have reported statistically significant deficits in the performance of ecstasy users relative to controls (Fox et al. 2001b; Gouzoulis-Mayfrank et al. 2000; McCardle et al. 2004; Parrott et al. 1998; Quednow et al. 2006; Reneman et al. 2001a, b, 2000; Thomasius et al. 2003; Yip and Lee 2005), which were often rather small (although not always; see Yip and Lee 2005). Other studies have not found any significant deficits on these particular tasks (Back-Madruga et al. 2003; Fox et al. 2001a; Golding et al. 2007; Schilt et al. 2008; Semple et al. 1999). For the CVLT, of the two studies which have reported results, one found ecstasy users performed significantly worse than controls who had not used ecstasy, but who had similar use of other drugs (Semple et al. 1999). The other study found no ecstasyrelated differences on the CVLT, although there was a trend towards significance in a small group of relatively heavier users of ecstasy ( $n=11$; minimum lifetime use of 60 ecstasy pills; Halpern et al. 2004). For Verbal Paired Associates, the two studies that reported results for the first learning trial in isolation, where performance accuracy is well below ceiling, found a significant recall deficit in ecstasy users on that trial (Montgomery et al. 2005; Ward et al. 2006). All remaining Verbal Paired Associate studies have reported results only of composite measures of all five learning recall trials combined. Results showed no difference between ecstasy users and controls (Bolla et al. 1998; Daumann et al. 2004; Gouzoulis-Mayfrank et al. 2003; Groth-Marnat et al. 2007; Rodgers 2000), but these findings cannot be relied upon given that performance typically reaches ceiling in controls by the second trial.

Taken together, these results are somewhat suggestive that behavioural memory deficits in human ecstasy users are more reliably obtained - and thus, presumably, largerin more complex explicit memory tasks (CVLT and Verbal Paired Associates with below-ceiling performance) than in simple explicit memory tasks (recall of single unrelated words). However, this conclusion cannot be drawn with any certainty, partly because of the lack of complexity range across the memory tasks previously reported, and partly because the comparisons are between studies conducted on different populations of ecstasy users. Given the geographical variability in the composition of ecstasy pills, usage patterns, other drug use, typical drug use settings (home or club) and genetic vulnerabilities (e.g. between different races or ethnic groups), it is crucial to compare across tasks using subjects drawn from a single geographical population, tested close together in time. The aim of the present study was to provide the first such investigation, examining long-term verbal memory performance and comparing performance across multiple levels of cognitive complexity.

We included multiple types of verbal memory test. Implicit memory was tested with a stem completion task (Schacter et al. 1989), in which subjects learn a list of words (e.g. calendar) and later complete three-letter stems (e.g. cal__ with the first word that comes to mind. Implicit memory is revealed as higher completion rates with target words for studied than unstudied items. Simple explicit memory was tested for lists of unrelated words, via stem-cued recall ("Complete cal with a word you saw on the study list") and also via free recall tasks including the Rey Auditory Verbal Learning Test (RAVLT). More complex explicit memory was tested with two types of task. One was the CVLT, for which we provide the first report of the degree of clustering of recall items by category (the SCI). The other was Verbal Paired Associates, with specific analysis of the first trial. Finally, for our most complex explicit memory task, a particularly demanding task was created-Verbal Triplet Associates-in which subjects learn triplets of words simultaneously (e.g. frogchair-apple) and at test are given the first word of each triplet as a cue (e.g. frog) to recall both others (chair and apple, in any order). This task was structured in a similar manner to the standard neuropsychological memory tasks (RAVLT, CVLT and Verbal Paired Associates) in having multiple cycles ("trials") of learning the entire list and being tested before learning again; the task was piloted to ensure that performance did not hit ceiling even on the final learning trial.

A final important feature of our design was that a cannabis user control group was also tested where differences between ecstasy users and non-drug using controls were found.

\section{Method}

\section{Participants}

Three samples were used in the present retrospective cohort study, all drawn from the general community in Canberra, Australia. Sample 1 comprised 32 ecstasy users and 29 nondrug using controls tested in 2002. Sample 2 comprised 30 
ecstasy users and 34 non-drug using controls tested in 2003. Sample 3 comprised 33 ecstasy users, 32 cannabis controls and 32 non-drug using controls tested in 20042005. Around the timeframe of testing, amounts of MDMA in ecstasy tablets seized by police in the Canberra region remained fairly stable (Proudfoot and Ward 2004). The samples were not mutually exclusive: sample 2 included 17 ecstasy users and 14 controls who were also included in sample 1; sample 3 included 19 ecstasy users and 16 controls who had been included in sample 2, of whom 11 ecstasy users and five controls had also been included in sample 1. Each sample received a mutually exclusive set of tests, such that no participants ever received the same test twice. Most participants were recruited using the respondent-driven "snowball" sampling technique (Wang et al. 2005). All gave informed consent. The studies were approved by the Australian National University Human Research Ethics Committee and were performed in accordance with the ethical standards laid down in the 1964 Declaration of Helsinki.

Participants were assessed on drug use history, demographic variables, estimated IQ and mental health and personality variables, using measures and methods described in Brown et al. (2007). Drug use history (including ecstasy, alcohol, cannabis and amphetamines) was obtained for each participant using a timeline interview based on Anglin et al. (1993). Anglin et al. (1993) showed this method is a valid and moderately reliable means of obtaining a drug use history for information between 10 and 14 years prior to assessment. In one study, the self-reported drug histories of 323 narcotics users were collected on two occasions 10 years apart. A comparison of the self-reported drug use for the 4-year period prior to the first interview showed significant correlations of .63 and .71 for daily narcotics use and abstinence. Recollections for infrequent events (including daily non-narcotics use $(r=.2, p<.01)$ and heavy alcohol use $(r=.48, p<.01))$ were less reliable but were enhanced by disaggregating the data into 3-month portions.

In the present study, the timeline method was used to obtain estimates of lifetime dose, abstinence since last use, maximum typical dose during their heaviest period of use and maximum ever dose on any given occasion for all of the drugs listed, except for cannabis, hallucinogens and inhalants which were recorded in the number of 'units' administered per occasion in light of the difficulties in qualifying amount used on any particular administration. A unit was defined as a discrete administration of the drug which may be repeated several times on any given occasion.

Our demographic variables were age, sex and highest level of education attained. Estimated premormid IQ was calculated from the number of reading errors on the Contextual AusNART (Lucas et al. 2003). Mental health was assessed using the Brief Symptom Inventory (BSI,
Derogatis 1993). Personality was assessed using the Sensation Seeking Scale (SSS, Zuckerman 1994), which has been shown to have a strong heritable component and to predict drug use (Dughiero et al. 2001; Zuckerman 1994; although see de Win et al. 2006).

Relevant characteristics of each group are summarised in Tables 2 and 3. Table 2 shows that the groups within each sample were closely matched on sex, age and estimated IQ, although the tendency for ecstasy users to have slightly lower estimated IQ than controls reached statistical significance in samples 1 and 2. Regarding drug use, drug-using cohorts were required to be abstinent from ecstasy and all other illicit drugs for at least 2 weeks, except cannabis for which they were required to have been abstinent for at least 2 days and were, on average, abstinent for considerably longer (Tables 2 and 3). Some incidental use of cannabis was tolerated in the non-drug using control groups due to the difficulty in finding people who had never tried cannabis; similarly, some incidental use of ecstasy was tolerated in the cannabis-control group (see Table 2 for details of amounts) due to the difficulty in finding drug users who had never tried ecstasy. Most ecstasy users had also used a variety of other drugs, including amphetamines, as shown in Tables 2 and 3. All variables (demographic and non-ecstasy drug use) were treated as potential covariates in all statistical analyses (see later statistical analysis section).

After completing the testing of sample 1, it was decided to target relatively heavier ecstasy users in samples 2 and 3 . For both these samples, the inclusion criterion was a minimum lifetime ecstasy use of 100 ecstasy tables reported in a screening phone call.

\section{Tasks}

Full details of novel tasks are available in Brown (2005).

Implicit memory: stem completion task (sample 1) Stimuli were single words, unrelated to each other in semantic content and not used in any other test in the session. During the study phase, the 12 words were presented one at time on a computer monitor, at a rate of one word every $3.5 \mathrm{~s}$ and read aloud by the participant. Participants simultaneously performed a divided attention task, namely odd-oreven digit monitoring (derived from Schmitter-Edgecombe and Nissley 2000); this was done to prevent strategic encoding at study, thus providing a good measure of implicit memory (Murphy et al. 2003). Learning for this divided attention implicit condition was interspersed with learning a different set of 12 items for a full-attention implicit condition that is not reported here (ecstasy effects did not differ across the two versions; for details, see Brown 2005). Each list was presented twice. There was then a 3-6-min filled delay before proceeding to the test phase. 
Table 2 Key demographic and drug use characteristics of cohorts in each sample ( $S E$ standard error)

\begin{tabular}{|c|c|c|c|c|c|c|c|}
\hline & \multicolumn{2}{|l|}{ Sample 1} & \multicolumn{2}{|l|}{ Sample 2} & \multicolumn{3}{|l|}{ Sample 3} \\
\hline & $\begin{array}{l}\text { Non-drug using } \\
\text { controls }(n=29) \\
\text { Mean }(\mathrm{SE})\end{array}$ & $\begin{array}{l}\text { Ecstasy } \\
\text { users }(n=32) \\
\text { Mean (SE) }\end{array}$ & $\begin{array}{l}\text { Non-drug using } \\
\text { controls }(n=34) \\
\text { Mean }(\mathrm{SE})\end{array}$ & $\begin{array}{l}\text { Ecstasy } \\
\text { users }(n=30) \\
\text { Mean (SE) }\end{array}$ & $\begin{array}{l}\text { Non-drug using } \\
\text { controls }(n=33) \\
\text { Mean }(\mathrm{SE})\end{array}$ & $\begin{array}{l}\text { Cannabis } \\
\text { controls }(n=32) \\
\text { Mean }(\mathrm{SE})\end{array}$ & $\begin{array}{l}\text { Ecstasy } \\
\text { users }(n=32) \\
\text { Mean (SE) }\end{array}$ \\
\hline Sex (male, \%) & $52 \%$ & $62 \%$ & $65 \%$ & $63 \%$ & $64 \%$ & $66 \%$ & $66 \%$ \\
\hline Age (years) & $24.0(7.9)$ & $22.5(5.3)$ & $23.2(0.7)$ & $23.2(0.7)$ & $23.5(0.7)$ & $23.6(0.9)$ & $23.5(0.7)$ \\
\hline $\begin{array}{l}\text { Highest level of } \\
\text { education attained }\end{array}$ & $3.3(0.6)$ & $3.2(0.5)$ & $3.4(0.1)$ & $3.2(0.1)$ & $3.4(0.1)$ & $3.2(0.1)$ & $3.2(0.1)$ \\
\hline Estimated IQ & $108.3(4.4)^{\mathrm{E}}$ & $104.8(5.4)^{\mathrm{N}}$ & $107.4(0.8)^{\mathrm{E}}$ & $104.1(1.0)^{\mathrm{N}}$ & $106.5(0.9)$ & $106.8(1.0)$ & $104.1(0.9)$ \\
\hline Ecstasy (tablets) & & & & & & $(n=16)^{\mathrm{d}}$ & \\
\hline Lifetime dose & - & $116(23)$ & - & $394.5(123.0)$ & - & $6(1)^{\mathrm{E}}$ & $384(109)^{\mathrm{C}}$ \\
\hline Abstinence (days) & - & $81(34)$ & - & $55.8(15.9)$ & - & $350(84)^{\mathrm{E}}$ & $37(7)^{\mathrm{C}}$ \\
\hline Max monthly dose $\mathrm{e}^{\mathrm{c}}$ & - & $6.04(7.05)$ & - & $19.0(5.2)$ & - & $0.4(0.2)^{\mathrm{E}}$ & $19.8(4.7)^{\mathrm{C}}$ \\
\hline Max ever dose & - & $4.06(2.41)$ & - & $5.8(0.8)$ & - & $1.2(0.2)^{\mathrm{E}}$ & $6.5(0.7)^{\mathrm{C}}$ \\
\hline \multicolumn{8}{|l|}{ Alcohol (std. drinks) } \\
\hline Lifetime dose & $1,486(582)^{\mathrm{E}}$ & $4,172(879)^{\mathrm{N}}$ & $1,023(226)^{\mathrm{E}}$ & $4,846(771)^{\mathrm{N}}$ & $749(208)^{\mathrm{EC}}$ & $3,060(557)^{\mathrm{N}}$ & $4,748(791)^{\mathrm{N}}$ \\
\hline Abstinence (days) & $9(10)$ & $7(22)$ & $17(6)$ & $5(1)$ & $170(104)$ & $26(16)$ & $29(18)$ \\
\hline Max monthly dose $\mathrm{e}^{\mathrm{c}}$ & $29.1(8.1)^{\mathrm{E}}$ & $92.5(16.4)^{\mathrm{N}}$ & $27.0(5.9)^{\mathrm{E}}$ & $122.4(17.5)^{\mathrm{N}}$ & $25(6)^{\mathrm{EC}}$ & $76(10)^{\mathrm{NE}}$ & $124(17)^{\mathrm{NC}}$ \\
\hline Max ever dose & $11.0(1.4)^{\mathrm{E}}$ & $18.7(1.3)^{\mathrm{N}}$ & $14.2(1.5)^{\mathrm{E}}$ & $20.9(1.40)^{\mathrm{N}}$ & $12(1)^{\mathrm{EC}}$ & $19(1)^{\mathrm{NE}}$ & $27(2)^{\mathrm{NC}}$ \\
\hline $\begin{array}{l}\text { Cannabis } \\
\quad \text { (administrations }^{\mathrm{b}} \text { ) }\end{array}$ & $(n=9)^{\mathrm{d}}$ & & $(n=11)^{\mathrm{d}}$ & & $(n=14)^{\mathrm{d}}$ & & \\
\hline Lifetime & $7(2)$ & $1,407(480)$ & $3(1)$ & $1,657(364)$ & $4.8(1)^{\mathrm{EC}}$ & $1,208(303)^{\mathrm{N}}$ & $2,694(780)^{\mathrm{N}}$ \\
\hline Abstinence (days) & $1,626(863)^{\mathrm{E}}$ & $148(57)^{\mathrm{N}}$ & $1,591(498)$ & $119(50)$ & $1,427(449)^{\mathrm{EC}}$ & $36(18)^{\mathrm{N}}$ & $187(86)^{\mathrm{N}}$ \\
\hline Max monthly dose ${ }^{\mathrm{c}}$ & $0.2(0.2)$ & $50.2(16.9)$ & $0.1(0.0)$ & $59(13.6)$ & $0.2(0.0)^{\mathrm{EC}}$ & $43.8(8.2)^{\mathrm{NE}}$ & $103(25)^{\mathrm{NC}}$ \\
\hline Max ever dose & $1.00(0.0)^{\mathrm{E}}$ & $5.7(0.96)^{\mathrm{N}}$ & $1.1(0.1)$ & $6.5(0.9)$ & $1.1(0.1)^{\mathrm{EC}}$ & $5.03(0.5)^{\mathrm{NE}}$ & $7.56(1.1)^{\mathrm{NC}}$ \\
\hline Amphetamines $\left(\right.$ grams $\left.^{\mathrm{b}}\right)$ & & & & & & $(n=14)^{\mathrm{d}}$ & \\
\hline Lifetime dose & - & $19.9(37.7)$ & - & $51.0(81.0)$ & - & $5.6(3.7)^{\mathrm{E}}$ & $59.1(15.4)^{\mathrm{C}}$ \\
\hline Abstinence (days) & - & $216(240)$ & - & $230.8(332.8)$ & - & $1,316(445)^{\mathrm{E}}$ & $292(99)^{\mathrm{C}}$ \\
\hline Max monthly dose ${ }^{c}$ & - & $3.0(7.7)$ & - & $4.3(7.8)$ & - & $0.5(0.5)^{\mathrm{E}}$ & $2.97(0.7)^{\mathrm{C}}$ \\
\hline Max ever dose & - & $1.0(1.1)$ & - & $1.5(1.4)$ & - & $0.5(0.2)$ & $1.64(0.4)$ \\
\hline
\end{tabular}

${ }^{\mathrm{a}} 1$ =year 10 (middle secondary education), 2=year 12 (upper secondary education), 3 =bachelor undergraduate degree and $4=$ post-graduate degree

${ }^{\mathrm{b}}$ Dose measurements explained briefly in text and in detail in Brown et al. (2007)

${ }^{\mathrm{c}}$ The maximum average dose per month within any period in their timeline, which represents the typical monthly dose during their heaviest period of use

${ }^{\mathrm{d}}$ The number of participants in this cohort with incidental use of this drug. Incidental use in this cohort was tolerated in order to obtain a sufficient cohort size. The statistics below relate only to this subset of participants

${ }^{\mathrm{N}} p<.05$ compared to non-drug using controls

${ }^{\mathrm{C}} p<.05$ compared to cannabis controls

${ }^{\mathrm{E}} p<.05$ compared to ecstasy users

In the test phase, 48 three-letter stems were presented, each of which was unique within the experiment, did not constitute a word in its own right and could be completed to form at least five different words (for details of stimulus words, see McKone and French 2001). Half of the stems corresponded to words presented during the study phase (studied target words), and half corresponded to words that had not been presented (unstudied target words). Studiedunstudied status of particular items was counterbalanced across participants. The instructions were to complete the stems as quickly as possible with the first word that came to mind. The implicit memory score was the percentage of studied stems completed with target words (primed condition) minus the percentage of unstudied stems completed with target words (baseline condition). Note baseline completion rates were low and not statistically different between controls $(M=4.5 \%, \mathrm{SE}=1.0 \%)$ and ecstasy users $(M=5.7 \%, \mathrm{SE}=1.2 \%), t(59)=0.70, p=.49$. 
Table 3 Additional drug use characteristics of cohorts in each sample (SE standard error)

\begin{tabular}{|c|c|c|c|c|}
\hline & \multirow{2}{*}{$\begin{array}{l}\text { Sample } 1 \\
\text { Ecstasy users }(n=32)\end{array}$} & \multirow{2}{*}{$\begin{array}{l}\text { Sample } 2 \\
\text { Ecstasy users }(n=30)\end{array}$} & \multicolumn{2}{|l|}{ Sample 3} \\
\hline & & & Cannabis controls $(n=32)$ & Ecstasy users $(n=32)$ \\
\hline Cocaine (grams ${ }^{\mathrm{a}}$ ) & & $(n=22)$ & $(n=5)$ & $(n=27)$ \\
\hline Lifetime dose & $4.9(7.6)$ & $6.2(9.4)$ & $1.0(0.3)$ & $5.7(1.7)$ \\
\hline Abstinence (days) & $354.5(276.2)$ & $439.5(438.7)$ & $745.7(169.2)$ & $332.5(61.0)$ \\
\hline Max monthly dose ${ }^{\mathrm{b}}$ & $0.5(0.8)$ & $0.6(0.7)$ & $0.10(0.0)$ & $0.48(0.1)$ \\
\hline Max ever dose & $0.9(0.8)$ & $0.8(0.7)$ & $0.41(0.1)$ & $0.93(0.2)$ \\
\hline Any hallucinogen (administrations ${ }^{\mathrm{a}}$ ) & & $(n=28)$ & $(n=14)$ & $(n=31)$ \\
\hline Lifetime dose & $20(22.7)$ & $36.4(43.7)$ & $12.3(5.7)$ & $27.62(7.1)$ \\
\hline Abstinence (days) & $506.8(1,081.1)$ & $417.1(687)$ & $1,356.5(273.0)$ & $368.81(100.5)$ \\
\hline Max monthly dose $\mathrm{e}^{\mathrm{b}}$ & $1(1.2)$ & $1.5(1.6)$ & $0.5(0.3)$ & $2.6(1.5)$ \\
\hline Max ever dose & $2.1(2.1)$ & $3.4(4)$ & $1.4(0.4)$ & $2.4(0.4)$ \\
\hline Any inhalant (administrations ${ }^{\mathrm{a}}$ ) & & $(n=21)$ & $(n=9)$ & $(n=26)$ \\
\hline Lifetime dose & $26.9(54.8)$ & $33.9(61.0)$ & $9.8(4.0)$ & $33.2(11.8)$ \\
\hline Abstinence (days) & $1,055.1(1,352.4)$ & $880.9(1,391.3)$ & $2,170.0(628.2)$ & $613.15(207.5)$ \\
\hline Max monthly dose $\mathrm{e}^{\mathrm{b}}$ & $1.6(1.9)$ & $1.4(1.5)$ & $0.4(0.2)$ & $1.9(0.56)$ \\
\hline Max ever dose & $6.6(11.7)$ & $5.7(9.1)$ & $1.7(0.5)$ & $4.7(1.6)$ \\
\hline
\end{tabular}

${ }^{a}$ Dose measurements explained briefly in text and in detail in Brown et al. (2007)

${ }^{b}$ The maximum average dose per month within any period in their timeline, which represents the typical monthly dose during their heaviest period of use

During the test phase, two standard methods were employed to ensure the stem completion task provided the purest possible measure of implicit memory, uncontaminated by participants attempting to use deliberate retrieval from the study list. First, the test phase was presented as an ostensibly unrelated task. Second, an explicit memory contamination questionnaire followed the test (McKone and French 2001). This was used to exclude one participant who reported attempting to complete stems via deliberate reference to the study list (this participant was replaced by a new participant).

Simple explicit memory: stem-cued recall (sample 1) This task (subsequently referred to as Stem-cued Recall Test 1) was identical in procedure to the implicit memory task except that (a) a different set of word stimuli was used, (b) divided attention was not used at study (i.e. there was no digit monitoring task), and (c) the instructions were for participants to complete stems with words they had learned on the study list and to leave stems blank where this was not possible. Memory was measured as hits (correct completions) minus false alarms (chance completions of unstudied stems with target words; note false alarm rates were extremely low).

Simple explicit memory: stem-cued recall (sample 2) Sample 2 participants were tested on two stem-cued recall tests (both different from the stem-cued recall test used with sample 1), with the aim of replicating sample 1 findings in heavier ecstasy users (i.e. sample 2 rather than sample 1) and at higher task performance levels. Both tests comprised only full attention at study (rather than interspersing learning phases for full- and divided-attention versions, as in sample 1). In Stem-cued Recall Test 2, the learning phase presented the list of 12 words once through. In Stem-cued Recall Test 3, the learning phase presented the word list twice through. The stimulus words were different in each test and different from those used in Stem-Cued Recall Test 1. In all other respects, Stem-cued Recall Tests 2 and 3 were identical to Stem-cued Recall Test 1.

Simple explicit memory: written free recall (sample 2) This test used the same procedure as Stem-cued Recall Test 2 (i.e. once through the list of 12 words), except that another new set of word stimuli was used, and the test phase required written free recall.

Simple explicit memory: Rey Auditory Verbal Learning Task (sample 2) The RAVLT is a standard neuropsychological test measuring free recall for single unrelated words, across multiple learning-test trials. The test was administered according to standard instructions (Lezak et al. 2004) using only 'list A' (i.e. no interference list) and only immediate recall trials. The list of words is read aloud by the experimenter at a rate of one word per second in a monotone voice. The participant is then asked to recall as many of the words as they can, in any order. Once they have exhausted 
their responses, the learning and testing procedure are repeated a further four times (making a total of five repetitions). The score for each trial is the number of words correctly recalled from the study list (out of 15).

Moderate complexity explicit memory: Verbal Paired Associates and the California Verbal Learning Test (sample 3) The Verbal Paired Associates (from Wechsler Memory Scales III, Wechsler 1997) and CVLT (Delis et al. 1987) were standard neuropsychological tests conducted according to the manufacturer's instructions. The Verbal Paired Associates task uses a multiple learn-test trial structure similar to the RAVLT and CVLT. The stimuli consist of pairs of words that would not normally be associated (e.g. truck-arrow). The experimenter reads aloud each word pair, taking $2 \mathrm{~s}$ to read each pair, with a pause of approximately $2 \mathrm{~s}$ between each word pair. At test, the experimenter reads aloud the first word from each word pair, to which the participant is asked to verbally respond with the paired word from the study phase. The score for each trial is the number of correctly recalled paired-words, out of eight, on each of the four learn-test trials. The delayed condition of the Verbal Paired Associates was run but is not reported due to ceiling effects (most subjects in both cohorts scored 8/8).

The CVLT is a test of explicit memory for a list of single words, much like the RAVLT, except that in the CVLT, the words are drawn from four distinct semantic categories (clothing, tools, fruit and spices-and-herbs). In the initial two sections of the CVLT (immediate and short delay recall), no reference is made to the semantic categories represented in the word list, either while learning the word list or during the test. Participants first learn and then recall a list of 16 words across five learn-test trials read aloud by the experimenter at a rate of approximately one word per second; scores on each test trial in this stage (Immediate) are the number correctly recalled words out of 16 . An interference trial is then conducted (not reported here) using a different word list, which is based on two of the original semantic categories (fruit and spices-and-herbs) and two new categories (appliances and fish). Then, two 'short delayed' tests of the recall of the original word list are conducted. The first of these is an oral verbal-free recall test (short delay recall; scores are the number correct out of 16). The second is a category-cued recall test in which the experimenter names each of the semantic categories in turn, and for each category, the participant responds with all of the words they can recall from that category (short delay cued recall; scores are again the number correct out of 16). Following a filled delay of approximately 20-30 min, without any further exposure to the word list, the participant is again tested on their free- and category-cued recall of the original word list (long delay recall and long delay cued recall; scores are the number correct out of 16 for each). In the three uncued stages, the list-based SCI (Stricker et al. 2002) was also calculated (SCI immediate, SCI short delay and SCI long delay). This provides an index of the extent to which the participant clusters the words recalled by semantic category; scores range from -3 (no clustering at all) to 9 (complete clustering). The CVLT is classified here as being a "moderately complex" explicit memory task on the basis of Savage et al. (2001), who found that prefrontal activation was higher when participants used four semantic category cues in a CVLT-type test than in free recall of a list of unrelated words in a RAVLTtype test.

Highest complexity explicit memory: Verbal Triplet Associates task (sample 3) This was a novel task in which participants learn a list of ten triplets of words (see Table 4). The words were not used in any of the other tests, were not from semantic categories used in the CVLT and were unrelated to drug use. Words in a given triplet were unrelated to each other and were from different semantic categories (Casey and Heath 1988). The list length of ten triplets was determined based on pilot testing to avoid both floor and ceiling effects in non-drug using controls. The procedure consisted of five consecutive learn-test cycles ("trials"). On each trial, the study phase consisted of the experimenter reading aloud the list of word triplets in a monotone voice at a rate of approximately $1.5 \mathrm{~s}$ to read each triplet, with a pause of approximately $1.5 \mathrm{~s}$ between each triplet (total of $30 \mathrm{~s}$ to read the entire list). Instructions to participants were to learn each triplet such that when they were later presented with the first word they would be able to recall the other two. During the memory tests, the experimenter read aloud the first word in each triplet (the 'cue'), and the participant was given $5 \mathrm{~s}$ to recall aloud as many as possible of the remaining two words in the triplet, in any order. Scores were thus out of 20 (10 triplets $\times 2$ recall words per triplet), on each of the five learn-test trials. Only the exact form of the study word was counted as a correct response (e.g. adding a plural or changing a noun to an adjectival form was counted as an error). At study, the order of words within each triplet was the same for all participants and all trials, and the order of the ten triplets was the same for all participants and differed across trials; at test, cues were presented in the order used in the study phase of that trial.

\section{Statistical analysis}

For tests with multiple learning trials, statistical analyses included a mixed model two-way analysis of variance (ANOVA), in which the repeated-measures variable was learning trial, and the between subjects variable was cohort (ecstasy users, cannabis controls and non-drug using 
Table 4 Stimuli for the Verbal Triplet Associates test, showing the three to-be-learned words in each triplet

\begin{tabular}{|c|c|c|c|c|c|c|c|}
\hline \multicolumn{3}{|l|}{ Triplets } & \multicolumn{5}{|c|}{ The order of the presentation of triplets at study and the order of the presentation of cues at test } \\
\hline Word 1 (cue) & Word 2 & Word 3 & Trial 1 & Trial 2 & Trial 3 & Trial 4 & Trial 5 \\
\hline Rugby & Bike & Pistol & First & Ninth & Sixth & Ninth & First \\
\hline Tram & Rabbit & Dentist & Second & Fifth & First & Fifth & Tenth \\
\hline Lego & Neck & Wattle & Third & Eighth & Ninth & Eighth & Fourth \\
\hline Shoulder & Tulip & Seagull & Fourth & Second & Tenth & Second & Seventh \\
\hline Clerk & Cannon & Tango & Fifth & Third & Third & Seventh & Second \\
\hline Finch & Ballet & Fridge & Sixth & Fourth & Second & Fourth & Ninth \\
\hline Lamp & Blocks & Maple & Seventh & First & Fifth & First & Sixth \\
\hline Lily & Elbow & Boat & Eighth & Tenth & Fourth & Third & Fifth \\
\hline Jazz & Baseball & Snake & Ninth & Seventh & Eighth & Tenth & Eighth \\
\hline Goat & Plumber & Willow & Tenth & Sixth & Seventh & Sixth & Third \\
\hline
\end{tabular}

controls). For single measure variables (e.g. the delayed recall test in the CVLT), statistical analysis included a oneway ANOVA on the memory measure as a function of cohort (ecstasy users, cannabis controls where relevant and non-drug using controls). In either case, a priori (planned) contrasts were conducted to determine the statistical significance of any difference in performance between the cohorts. No post hoc testing was conducted.

For all tests, covariate analysis was conducted in two stages. In the first stage, all demographic, mental health and personality variables were considered. Bivariate correlations were used to eliminate variables which showed no relationship to the outcome measure. The remaining variables were introduced into an analysis of covariance (ANCOVA) analysis. Backward elimination of the covariates was then conducted (based on backward elimination of variables in regression modelling; Kleinbaum et al. 1988) until only those covariates (if any) which had a statistically significant contribution to the model remained.

\section{Results}

The major results were that (a) more cognitively complex memory tasks were associated with clearer ecstasy-related deficits on memory (Fig. 1a), (b) ecstasy users employed substantially weaker strategic processing than both non-drug using and cannabis controls as revealed by semantic clustering scores on the CVLT (Fig. 1b), and (c) where scores were unaffected by ceiling effects, performance of ecstasy users failed to reach that of controls even after multiple repeated learning trials (Fig. 2d).

Statistical analyses supporting these descriptions are now described. The main effects of cohort, as well as contrasts between specific cohorts (as reported by SPSS 2004) both before and after the covariate analysis, are reported in
Table 5 (implicit memory and simple explicit memory tasks) and Table 6 (complex explicit memory tasks). Covariates that were significant in each analysis (and thus adjusted for in that analysis) are stated in the text; where covariates are not mentioned, none was significant. (Full details of the extensive covariate analyses are available in Brown 2005).

Implicit memory: stem completion task Implicit memory, involving the lowest level of cognitive complexity and relying only on perceptual processing brain regions, showed no ecstasy-related deficit (Fig. 1a and Table 5). That is, performance of the ecstasy users in sample 1 did not differ from the non-drug using controls on this task.

Single unrelated words: stem-cued recall, written free recall and RAVLT The next level of cognitive complexity was simple explicit memory tasks, testing recall for single unrelated words: these tasks critically involve the hippocampus as well as perceptual areas but have lower prefrontal involvement than the more complex explicit memory tasks (as discussed in the "Introduction", Savage et al. 2001). For these types of tests, our results (Fig. 1a and Table 5) consistently showed either no ecstasy-related memory deficit or a very small difference between ecstasy users and non-drug user controls that was not statistically significant once covariates were taken into account.

Importantly, this result was obtained with both higher average ecstasy use (sample 2) as well as lower average ecstasy use (sample 1). Further, it was obtained regardless of whether overall performance level on the task was high (Stem-cued Recall Test 3), medium (Stem-cued Recall Test 2) or lower (Stem-cued Recall Test 1 and Written Free Recall). Finally, it was obtained with both free recall and cued recall (cued by part of the target word). Thus, in this particular geographical population, it appears to be a robust finding 
Fig. 1 a Summary of key memory findings on overall memory performance, showing that in a common geographical population, deficits in ecstasy users relative to controls are more marked in complex memory tasks (involving significant frontal lobe contributions) than in simple memory tasks. b Evidence that the poor memory performance on ecstasy users on the California Verbal Learning Test corresponds to less utilisation of the most appropriate memory strategy (i.e. semantic clustering). Single asterisk $=$ ecstasy cohort significantly different from one or both control cohorts at $p<.05 ; n s=$ ecstasy cohort not significantly different from controls, with all applicable $p$ 's $>.2$; significance values refer to results of the covariate analysis (where relevant).

Scores plotted are group means unadjusted for covariates; error bars show \pm 1 SEM
A. Task influences on Ecstasy-related deficits in memory performance.
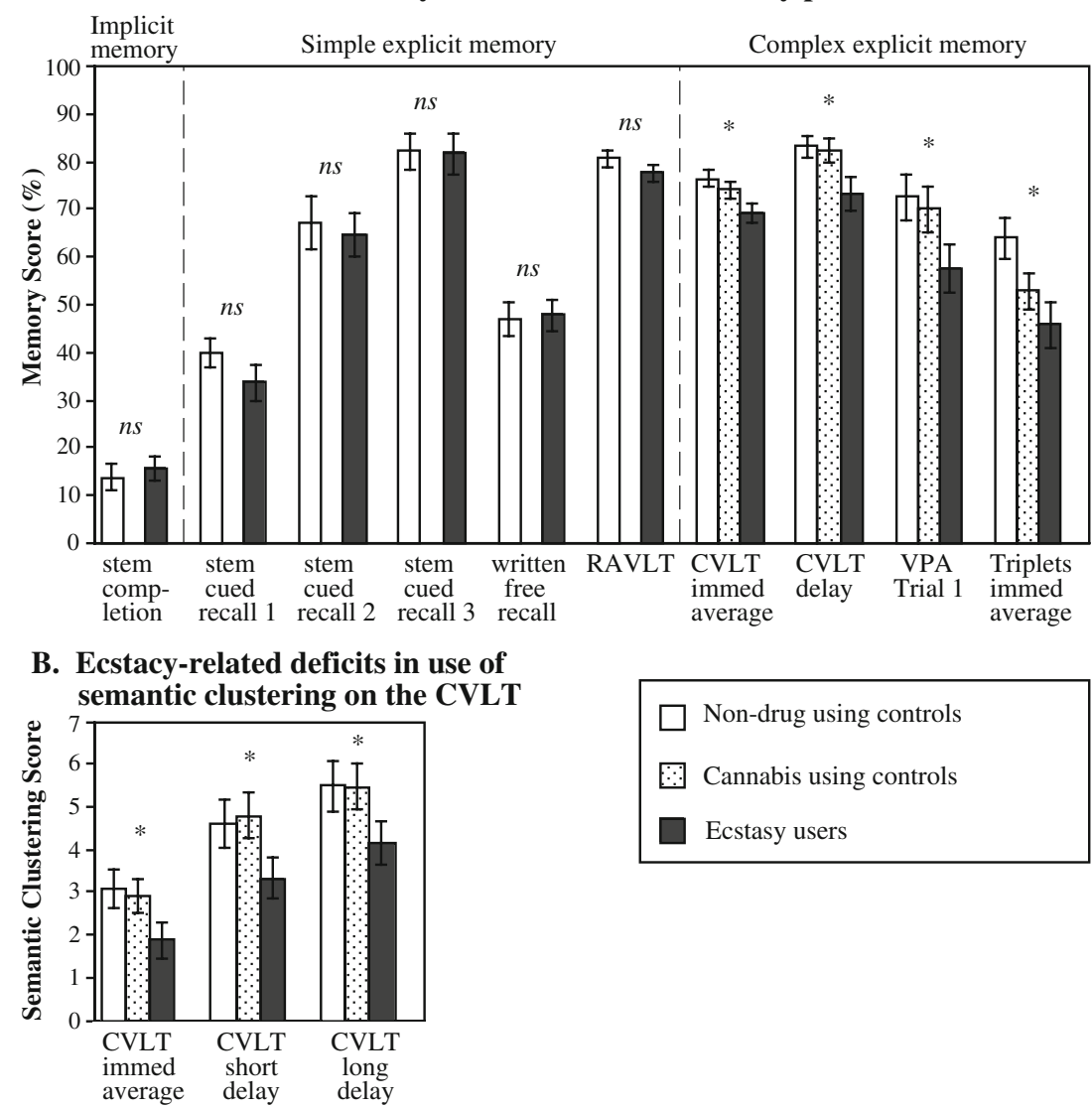

Non-drug using controls

Cannabis using controls

Ecstasy users that ecstasy-related deficits on simple explicit memory are very weak, at best.

California Verbal Learning Test On complex explicit memory tests that require significant contributions of the frontal cortex in addition to the hippocampus and perceptual areas, significant ecstasy-related deficits became apparent.

To begin, we report the "free recall" sections of the CVLT: that is, the situation where no mention is made to participants of the fact that the 16 study words can be grouped into four semantic categories (clothing, tools, fruit and spices-and-herbs), and participants are left to choose their own strategies, if any. In this situation, ecstasy users performed more poorly than both control groups (non-drug users and cannabis controls) with no significant differences between the two control groups (Fig. 1a and Table 6). Specifically, ecstasy users were significantly worse at recalling words than each control group at all three delays: total immediate free recall (collapsed over learning trials given that there was no interaction between trial and cohort, see Fig. 2a; covariate BSI obsessive-compulsive), short delay free recall (covariates BSI depression and estimated IQ) and long delay free recall (covariate BSI obsessivecompulsive). Thus, where participants' attention was not explicitly drawn to the potential relevance of grouping by semantic category, there were clear memory recall deficits in the ecstasy users.

We next report the semantic clustering results. These provide a measure of the extent to which, during free recall, participants grouped their responses during output by semantic category. Higher scores indicate greater grouping and thus greater use of the ideal memory strategy for the task. The SCI was calculated according to the list-based method (Stricker et al. 2002). Results (Table 6 and Fig. 1b) showed no differences between the two control groups (non-drug users and cannabis users) at any delay but showed clear evidence that ecstasy users exhibited less semantic clustering. Specifically, after controlling for covariates, ecstasy users exhibited significantly less semantic clustering than non-drug using controls in all delay conditions: SCI immediate (covariates SSS experience seeking and BSI obsessive-compulsive), SCI short delay (covariates SSS experience seeking and BSI obsessive-compulsive) and SCI long delay (covariates BSI phobic anxiety, SSS experience seeking and SSS boredom susceptibility). These covariate analyses also revealed less semantic clustering than the cannabis user control group for the two shorter delays (SCI immediate and SCI short delay), with a trend in the same direction at the longest delay (SCI long delay). Thus, ecstasy users were consistently impaired in their spontaneous 
Fig. 2 Learning effects across trials for (a) California Verbal Learning Test performance, (b) California Verbal Learning Test semantic clustering index, (c) Verbal Paired Associates and (d) Verbal Triplet Associates. Results show that ecstasy users performed worse than controls and used less semantic clustering, even after multiple learning trials (except where performance reached ceiling in the Verbal Paired Associates). Scores plotted are group means unadjusted for covariates; error bars show \pm 1 SEM
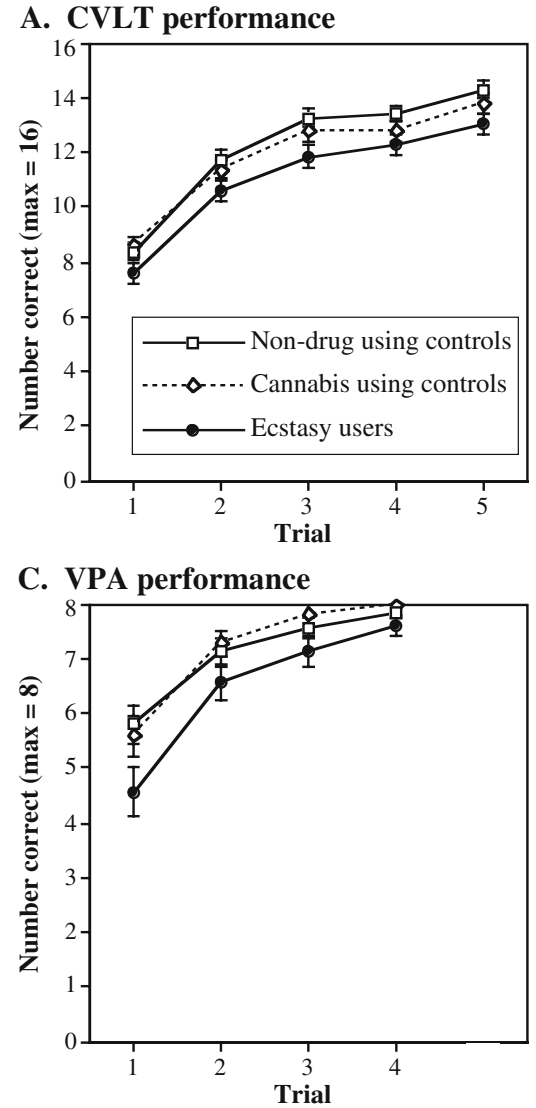

B. CVLT semantic clustering

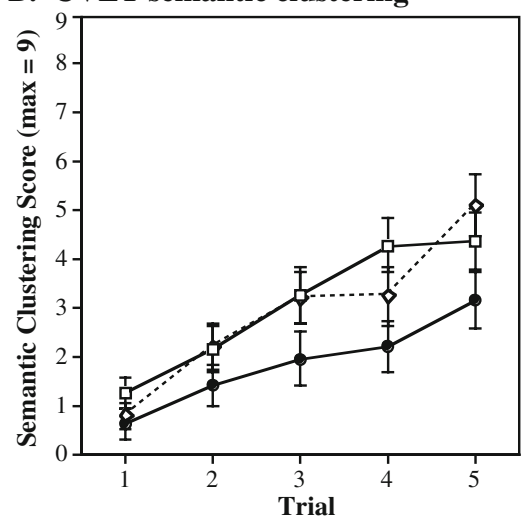

D. Triplet Associate Performance

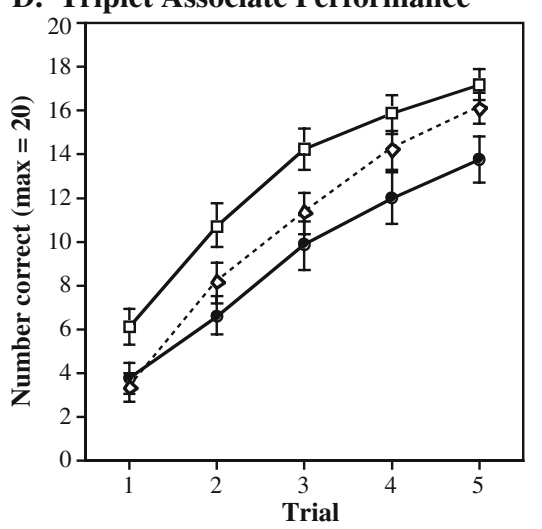

implementation of the ideal strategy for supporting CVLT performance. Moreover, this pattern was consistent across all learning trials (Fig. 2b).

While the SCI measure assesses participants' spontaneous use of category structure as a memory cue, ability to use this cue by instruction is also assessed in the CVLT, via the category-cued recall tests (short delay cued recall and long delayed cued recall in Table 6). Participants were given the name of each of the four semantic categories in turn and asked to recall the learned items from that category. Results (Table 6) showed no evidence of ecstasy-related deficits. Specifically, small ecstasy-related deficits (see means) that were significant in the initial analyses disappeared completely after controlling for covariates (BSI boredom susceptibility for short delay cued recall and BSI obsessive-compulsive for long delay cued recall).

Verbal Paired Associates As expected, a considerable ceiling effect was evident on Verbal Paired Associates immediate recall trials 2-4 (Fig. 2c).

Consequently, the only condition in which cohort effects could fairly be examined was immediate recall trial 1. A priori analysis of trial 1 (Table 6) showed no difference between the two control groups (non-drug users and cannabis users). Ecstasy users showed a memory deficit that was statistically significant relative to cannabis controls and approached significance relative to non-drug using controls (covariate was BSI positive symptom distress index).

Verbal Triplet Associates task Figure 1d shows that the Verbal Triplet Associates task produced the largest mean difference between ecstasy users and non-drug using controls of any of our tasks. Figure $2 \mathrm{~d}$ shows that performance was sufficiently away from ceiling (and floor) to allow fair examination of cohort effects on all five trials.

Statistical comparisons of cohort effects on memory performance were complicated by interactions between covariates (alcohol usage measures) and trial, meaning that cohort effects could not be analysed using contrasts on the overall two-way trial $\times$ cohort ANCOVA. Instead, it was necessary to analyse each trial separately. Results (Table 6 and Fig. 2d) showed that after accounting for covariates (across trials, these included estimated IQ, lifetime alcohol dose and maximum monthly alcohol dose), ecstasy users performed worse than non-drug using controls on all five trials individually, as well as averaged across all trials. Comparison to cannabis users, however, revealed a different pattern. Cannabis controls started on the first trial with a performance level that was as poor as that of ecstasy users and significantly poorer than non-drug users. Cannabis users then improved more rapidly across trials than ecstasy users. By trial 2, cannabis users' deficit relative to non-drug users had 
Table 5 Means (standard errors) and results of initial and covariate analysis for implicit memory and simple explicit memory tasks applied to samples 1 and 2

\begin{tabular}{|c|c|c|c|c|c|c|c|}
\hline \multirow[t]{2}{*}{ Test } & \multirow[t]{2}{*}{ Sample } & \multicolumn{2}{|l|}{ Mean (SE) } & \multicolumn{2}{|c|}{$\begin{array}{l}\text { Initial } \\
\text { analysis }\end{array}$} & \multicolumn{2}{|c|}{$\begin{array}{l}\text { Covariate } \\
\text { analysis }\end{array}$} \\
\hline & & Non-drug using controls & Ecstasy users & $F$ & $p$ & $F$ & $p$ \\
\hline \multicolumn{8}{|l|}{ Stem completion $(d f=1,59)$} \\
\hline Implicit memory score & 1 & $1.66(0.03)$ & $1.88(0.03)$ & 0.2 & .63 & - & - \\
\hline \multicolumn{8}{|l|}{ Stem-cued recall $(d f=1,62)$} \\
\hline Test 1 (two trial learning in a difficult memory task) & 1 & $4.77(0.03)$ & $4.04(0.04)$ & 1.6 & .21 & - & - \\
\hline Test 2 (one trial learning in an easier memory task) & 2 & $8.24(0.31)$ & $7.77(0.34)$ & 1.0 & .31 & - & - \\
\hline Test 3 (two trial learning in an easier memory task) & 2 & $9.68(0.25)$ & $9.53(0.34)$ & 1.2 & .73 & - & - \\
\hline \multicolumn{8}{|l|}{ Written free recall $(d f=1,62)$} \\
\hline Immediate & 2 & $5.62(0.29)$ & $5.30(0.30)$ & 0.6 & .45 & - & - \\
\hline \multicolumn{8}{|l|}{ RAVLT } \\
\hline Trial 1 & 2 & $8.74(0.45)$ & $7.77(0.40)$ & 2.51 & .12 & 1.13 & .29 \\
\hline Trial 2 & 2 & $11.56(0.38)$ & $10.70(0.46)$ & 2.11 & .15 & 0.35 & .55 \\
\hline Trial 3 & 2 & $13.21(0.32)$ & $11.90(0.44)$ & 5.97 & .02 & 2.34 & .13 \\
\hline Trial 4 & 2 & $13.71(0.24)$ & $13.03(0.29)$ & 3.15 & .08 & 0.39 & .54 \\
\hline Trial 5 & 2 & $14.21(0.17)$ & $13.73(0.27)$ & 2.36 & .13 & 0.55 & .46 \\
\hline Total immediate (all trials) & 2 & $61.41(1.29)$ & $57.13(1.61)$ & 4.41 & .04 & 1.31 & .26 \\
\hline
\end{tabular}

Significant differences between cohorts have $p$ values shown in italic

dropped to being non-significant, and they had developed a significant advantage compared to ecstasy users (Table 6). By trial 5, cannabis users had improved completely to control levels (Fig. 2d).

Dose dependence For each test producing a statistically significant difference between ecstasy users and controls, bivariate correlations (two-tailed, Pearson's $r$ ) were conducted between memory performance and drug use measures (including ecstasy, alcohol, cannabis and amphetamines). There were no statistically significant dose dependencies for any drug once covariates were taken into account (all $p$ 's $>.05$ ). (Details are available in Brown 2005). Note however that: our sample size was low in comparison to studies designed specifically to look for dose dependence, drug use measures were not normally distributed and the relevant tasks (all from sample 3) excluded users with ecstasy use at the low end of the range. Thus, the lack of dose dependence should not be taken as reliable.

Results relevant to across-sample comparisons Our claim of differences between simple and complex explicit memory tasks rests on the assumption that the observed differences reflect effects of the tasks rather than the samples of participants. Several analyses were therefore conducted to rule out a sample-based explanation. First, Table 2 shows that the mean ecstasy use of sample 3 (who performed the complex tasks) was slightly lower than that of sample 2 (who performed the simple tasks); thus, the deficits on the complex tasks could not be attributed to greater ecstasy use. Second, although the ecstasy users in sample 3 had on average a slightly shorter period of abstinence ( $M=5.3$ weeks) than ecstasy users in sample 2 ( $M=8.0$ weeks), this difference was not statistically significant $(t(60)=1.11, p=.27)$, and also, in both samples, there were no statistically significant correlations between performance on any task with the length of abstinence (largest Pearson's $r=-.37, p=.17$ for AVLT total score). Third, we made use of the fact that there was partial overlap between the ecstasy users tested in samples 3 and 2. We split the sample 3 members into two subgroups: ecstasy users who participated in both samples 3 and 2 ("overlapping" ecstasy users, $n=19$ ) and those who participated only in sample 3 ("new" ecstasy users, $n=13$ ). Demographic and drug use properties of the two subgroups were very similar (smallest $p>.22$ ). Across all measures of the three complex explicit memory tasks (CVLT, Verbal Paired Associates and Verbal Triplet Associates), we then found no differences between the two subgroups of ecstasy users (for 13 statistical comparisons, all $p$ 's $>.30$ except for CVLT short delayed SCI which was $p=.09$ ). Both subgroups also showed the strongest deficit relative to controls on the most complex task (Verbal Triplet Associates, significant for "overlapping" users at $p=.03$ and for "new" users at $p=.01$ ). Finally, we confirmed that the overlapping subgroup showed no suggestion of deficits relative to controls on the simple explicit memory tasks of sample 2 (smallest $p=.49$ ). Together, these results provide strong evidence that differences in ecstasy 
Table 6 Means (standard errors), initial and covariate analysis for complex explicit memory tasks applied to sample 3, being the California Verbal Learning Test (CVLT), Verbal Paired Associates (VPA), and Verbal Triplet Associates (VTA)

\begin{tabular}{|c|c|c|c|c|c|c|c|c|c|c|c|c|c|}
\hline \multirow[t]{2}{*}{ Test } & \multirow[t]{2}{*}{$\mathrm{N}$} & \multirow[t]{2}{*}{$\mathrm{C}$} & \multirow[t]{2}{*}{ E } & \multicolumn{2}{|c|}{ Main effect } & \multicolumn{3}{|c|}{ Contrasts $(p)$} & \multicolumn{2}{|c|}{ Main effect } & \multicolumn{3}{|c|}{ Contrasts $(p)$} \\
\hline & & & & $F$ & $p$ & $\mathrm{~N}-\mathrm{C}$ & $\mathrm{C}-\mathrm{E}$ & $\mathrm{N}-\mathrm{E}$ & $F$ & $p$ & $\mathrm{~N}-\mathrm{C}$ & $\mathrm{C}-\mathrm{E}$ & $\mathrm{N}-\mathrm{E}$ \\
\hline \multicolumn{14}{|l|}{ CVLT } \\
\hline Immediate (total) ${ }^{\mathrm{a}}$ & $61.1(1.4)$ & $59.2(1.5)$ & $55.4(1.7)$ & 3.6 & .03 & .39 & .01 & .01 & 2.9 & .06 & .56 & .02 & .02 \\
\hline SCI immediate (total) & $15.3(2.2)$ & $14.5(2.1)$ & $9.3(2.1)$ & 2.3 & .11 & .78 & .04 & .05 & 4.1 & .02 & .13 & .01 & .01 \\
\hline Short delay recall & $12.8(0.4)$ & $12.5(0.5)$ & $11.1(0.5)$ & 4.3 & .02 & .65 & .01 & .01 & 6.3 & .10 & .74 & .03 & .04 \\
\hline SCI short delay & $4.6(0.6)$ & $4.8(0.5)$ & $3.3(0.5)$ & 2.3 & .11 & .81 & .04 & .09 & 3.0 & .05 & .46 & .02 & .02 \\
\hline Short delay cued recall & $13.3(0.4)$ & $12.9(0.5)$ & $12.0(0.4)$ & 2.2 & .12 & .65 & .05 & .04 & $<1$ & .52 & .40 & .43 & .28 \\
\hline Long delay recall & $13.3(0.4)$ & $13.2(0.4)$ & $11.7(0.5)$ & 4.0 & .02 & .85 & .01 & .01 & 3.4 & .04 & .87 & .01 & .03 \\
\hline SCI Long delay & $5.5(0.6)$ & $5.5(0.6)$ & $4.1(0.5)$ & 2.0 & .14 & .99 & .05 & .08 & 2.0 & .14 & .81 & .11 & .05 \\
\hline Long delay cued recall & $13.2(0.5)$ & $13.5(0.4)$ & $12.0(0.5)$ & 2.8 & .07 & .69 & .02 & .08 & 1.5 & .23 & .54 & .27 & .11 \\
\hline \multicolumn{14}{|l|}{ VPA } \\
\hline Trial $1^{\mathrm{b}}$ & $5.8(0.4)$ & $5.6(0.4)$ & $4.6(0.4)$ & 2.8 & .07 & .73 & .02 & .03 & 2.2 & .12 & .92 & .04 & .07 \\
\hline \multicolumn{14}{|l|}{ VTA } \\
\hline Immediate (total) ${ }^{\mathrm{c}}$ & $63.9(4.1)$ & $52.9(3.8)$ & $45.7(4.7)$ & 4.7 & .01 & .07 & .02 & .01 & 2.8 & .07 & .11 & .05 & .03 \\
\hline Trial 1 & $6.1(0.8)$ & $3.3(0.6)$ & $3.7(0.7)$ & 4.5 & .01 & .01 & .25 & .01 & 4.5 & .01 & .01 & .25 & .02 \\
\hline Trial 2 & $10.7(1.0)$ & $8.1(0.9)$ & $6.6(0.9)$ & 4.7 & .01 & .06 & .02 & .01 & 3.8 & .03 & .06 & .05 & .01 \\
\hline Trial 3 & $14.2(1.0)$ & $11.3(1.0)$ & $9.8(1.2)$ & 4.7 & .01 & .05 & .02 & .01 & 3.8 & .03 & .06 & .06 & .01 \\
\hline Trial 4 & $15.8(0.9)$ & $14.2(0.9)$ & $12.0(1.2)$ & 3.7 & .03 & .24 & .01 & .01 & 2.8 & .07 & .13 & .04 & .02 \\
\hline Trial 5 & $17.1(0.7)$ & $16.1(0.7)$ & $13.7(1.1)$ & 4.1 & .02 & .38 & .01 & .01 & 2.7 & .07 & .22 & .03 & .02 \\
\hline
\end{tabular}

$d f=(2,94)$ for all tests

$N$ non-drug using controls, $C$ cannabis controls, $E$ ecstasy users, $S C I$ list-based semantic clustering index

${ }^{a}$ Mixed model ANOVA analysis of immediate recall as function of cohort and trial. No significant interactions in either the initial or covariate analyses, $F$ 's $<1$, ns

${ }^{\mathrm{b}}$ Simple effects analysis on trial 1 only, due to heavily skewed distributions on trials 2 and 3 caused by marked ceiling effects

${ }^{\mathrm{c}}$ Mixed model ANOVA analysis of immediate recall as a function of cohort and trial found a significant interaction between cohort and trial, $F(8$, $218)=2.56, \mathrm{MSE}=8.33, p=.03$. Also, ANCOVA analysis revealed significant interactions between the maximum monthly alcohol dose and trial, $F(4,328)=8.54, \mathrm{MSE}=6.53, p<.001$, and between lifetime dose of alcohol and trial, $F(4,328)=3.64, \mathrm{MSE}=6.53, p=.02$. Therefore, simple effects analysis on each trial was conducted using univariate ANOVA/ANCOVA

$p$-values in italics were significant at $p<.05$

effects were due to the tasks, not the individuals, tested in samples 2 and 3 .

\section{Discussion}

Our study produced three major findings. First, our results support the hypothesis that behavioural deficits of memory in human ecstasy users are more marked on tasks that are more cognitively complex and which heavily load many brain areas including the frontal lobes rather than relying principally on the hippocampus and/or perceptual areas. Specifically, across multiple different tasks in samples drawn from a common geographical population, we found the following results. Memory deficits were absent in an implicit memory task (stem completion), which utilises perceptual areas only. Memory deficits were also absent or at most weak and not statistically significant after controlling for covariates, in simple explicit tasks (stem-cued recall and free recall of lists of unrelated words) which principally rely on perceptual areas plus the hippocampus, with relatively weak frontal lobe involvement (Savage et al. 2001; Spiers et al. 2001; Thiel 2003). However, deficits were clearly apparent in complex explicit memory tasks (CVLT, Verbal Paired Associates and Verbal Triplet Associates), which critically rely on strong frontal lobe contributions in addition to perceptual areas and the hippocampus (Posner et al. 1988; Roskies et al. 2001; Schreckenberger et al. 1998; Shaywitz et al. 1995). Indeed, we found particularly striking deficits in our most complex task (Verbal Triplet Associates).

Second, our results revealed ecstasy-related deficits in subject-initiated strategic processing. These results come from the SCI of the CVLT. Our CVLT findings were that 
(a) free recall memory in ecstasy users was poorer than in relevant control groups (both non-drug users and cannabis users); (b) this poor performance derived from ecstasy users' failure to implement the ideal memory strategy for the task, in that their free recall output showed a lack of semantic grouping of items relative to controls; and (c) this failure was specifically a failure of spontaneous implementation, in that experimenter cuing of the category structure removed the ecstasy-related memory deficit. These findings provide direct evidence that ecstasy users suffer a loss of deliberate memory strategies. Also, note the CVLT result coheres theoretically with the lack of ecstasy deficit in the RAVLT task. The RAVLT is structurally similar to the CVLT in most ways (i.e. it involves multiple learning-test trials and uses single word stimuli) but differs critically in that the stimulus words are not drawn from obvious groupings. Under these circumstances, control participants will not benefit, relative to ecstasy users, from their better spontaneous strategic processing, because there is no obvious strategy to implement.

Our final important finding was that ecstasy-related deficits on associative memory remained apparent even after multiple attempts to learn the same material. Previous findings from the Verbal Paired Associates task have suggested that ecstasy deficits might be merely a matter of poor learning from a single initial exposure, followed by rapid improvement to normal levels with repeated learning opportunities (Montgomery et al. 2005; Ward et al. 2006). However, when we introduced an associate task that was difficult enough that performance did not reach ceiling levels (our Verbal Triplet Associates task), we found that ecstasy users failed to show any evidence of improving to the level of non-drug users even after five opportunities to learn the material. This pattern contrasted with that found in cannabis users, who improved to normal levels.

\section{Comparison to previous studies}

As far as we are aware, our results are novel in providing (a) the first evidence of task complexity effects over four levels of cognitive complexity, (b) the first direct analysis of subject-initiated use of memory strategies by ecstasy users using the SCI associated with the CVLT, and (c) the first valid test comparing memory across multiple learning trials in the absence of ceiling effects, with results showing ecstasy users did not improve to control-level performance even after multiple learning opportunities. We can also compare results of specific individual tests to previous findings, where relevant results are available, and we do this now.

Regarding immediate memory for single unrelated words (e.g. RAVLT and similar tasks), of 15 previous studies reporting data for such tests, ten reported statistically significant ecstasy deficits (Fox et al. 2001b; Gouzoulis-
Mayfrank et al. 2000; McCardle et al. 2004; Parrott et al. 1998; Quednow et al. 2006; Reneman et al. 2001a, b, 2000; Thomasius et al. 2003; Yip and Lee 2005), which were often quite quantitatively small, and five found no significant deficits (Back-Madruga et al. 2003; Fox et al. 2001a; Golding et al. 2007; Schilt et al. 2008; Semple et al. 1999). Our own finding of very small and non-significant deficits is thus at the low end of the range of previous studies but is not inconsistent with previous evidence. We note that the reason for the different findings across the various studies remains unknown. One possibility is that it reflects geographical differences: for example, in patterns of drug use, drug use settings, drug composition and/or genetic vulnerabilities. It was for these reasons that in the present study, we have emphasised the need to make comparisons (in our case between tasks) within a single population of users and not across populations.

Regarding Verbal Paired Associates, our results replicate those of the two previous studies reporting individual-trial data (Montgomery et al. 2005; Ward et al. 2006), in showing a significant deficit in ecstasy users relative to controls on the first trial, but not on subsequent trials where performance reaches ceiling.

With respect to the CVLT, on the immediate recall measures, our results replicate findings of Semple et al. (1999) on deficits in ecstasy users compared to controls and the trend towards these same results in Halpern et al. (2004).

With respect to implicit memory, we are unaware of previous tests of implicit memory in ecstasy users. However, our finding of no ecstasy-related deficits is consistent with the general finding that implicit memory is more robust than explicit memory, including against acquired brain injury (e.g. Warrington and Weiskrantz 1970), as well as alcohol or cocaine abuse (Brunfaut and d'Ydewalle 1996; Curran et al. 2002; Curran and Morgan 2000; Jasiukaitis and Fein 1999).

\section{Validity of our major findings}

We now discuss potential limitations relevant to our three major findings. Regarding two of our novel findingsfailure of spontaneous strategy use on the CVLT and failure to improve to control levels with multiple learning trials on the Verbal Triplet Associates - the only question is whether the significant cohort effects we observed (i.e. significant differences between ecstasy users and controls) are attributable to ecstasy use per se rather than some other variable. We note that we were not able to demonstrate dose dependence. This would have provided the most powerful evidence for an ecstasy-related origin. However, the absence of such effects was not unusual or surprising given our sample size and exclusion of low-use ecstasy users in samples 2 and 3 ). Another limitation was that insufficient resources were 
available to confirm drug-free status at testing via toxicological investigations (e.g. hair analysis and urinalysis).

With respect to our third major finding - stronger ecstasy cohort deficits in more complex tasks - an additional issue arises. This is the validity of our across-sample comparisons. Despite the use of three different samples, there are several reasons to believe that our findings did indeed reflect task complexity effects and not sample differences. First, all samples were selected from the same geographical population and across a constrained time frame (3 years). Second, regarding amount of ecstasy used in the three samples, the only noticeable difference was between samples 1 and 2. The key result from those samples was replicated in both cases: that is, neither the lower-usage group (sample 1) nor the higher-usage group (sample 2) showed any significant deficit relative to controls on simple explicit memory tasks for single unrelated words (although we note that implicit memory was tested only in sample 1). Crucially, the presence of ecstasy-cohort deficits on the complex explicit memory tasks cannot be attributed to higher ecstasy use in the subject sample (sample 3) than in the sample that completed simple explicit memory tasks (sample 2), because in fact, sample 3 had slightly lower mean ecstasy use than sample 2. Third, it is unlikely the slightly shorter mean period of abstinence in sample 3 than sample 2 (the difference was not statistically significant) could account for the stronger deficits relative to controls in the complex tasks because duration of abstinence was uncorrelated with task performance. Fourth, the subset of ecstasy users who participated in both sample 3 and sample 2 showed (a) no difference from sample-3-only ecstasy users in their performance on the complex memory tasks and (b) no suggestion of any deficits relative to controls in the simple memory tasks. Together, we believe these findings make a strong case that our findings were due to task complexity and not sample differences.

\section{Theoretical interpretation of task complexity effects}

Our results argue that ecstasy-related memory deficits are stronger in more complex memory tasks than in simpler memory tasks. We now consider the possible theoretical interpretations of this effect, first in terms of the functional cognitive components of memory, and then in terms of the brain regions involved in memory.

In terms of functional cognitive components, our results from the CVLT support the interpretation that the reason for strong ecstasy-related deficits in complex memory tasks is that ecstasy users fail to implement, in a top-down selfinitiated manner, the deliberate memory strategies that are needed for good performance on these tasks. We obtained direct evidence for this interpretation in the context of the CVLT, where the ecstasy cohort showed significantly less semantic clustering of their free recall output than either non-drug users or cannabis users. These results imply there will be value in testing other types of memory strategies in future studies. Of particular interest would be the strategies known to contribute to good performance on associate learning tasks (i.e. Verbal Paired Associates and presumably our Verbal Triplet Associates test) - namely, the formation of sentences or visual images linking the otherwise unrelated items. Our results suggest that ecstasy users may implement such strategies less frequently, or less successfully, than controls. Given our CVLT findings, we would particularly expect ecstasy users to show a deficit in spontaneous use of such strategies. Whether they would show a deficit in ability to implement the strategies to instruction is less clear: our CVLT findings suggest perhaps not, but standard associate learning tasks limit the amount of study time participants have to generate linking relationships between the items, and ecstasy users have been shown to have deficits in processing speed (Croft et al. 2001; de Sola Llopis et al. 2008).

Turning to the brain regions involved in memory, our findings were that ecstasy-related deficits were stronger on tasks known to place heavier reliance on the frontal lobes than on tasks known to place weaker reliance on the frontal lobes. An open question is whether the complexity effects arise from the involvement of the frontal lobes per se- that is, that ecstasy simply causes more severe lasting changes to the frontal lobes than to other regions-or from the fact that complex memory tasks require strong collaboration between the frontal lobes and other memory-related structures. Possibly favouring the former interpretation, anatomical evidence in animals shows that frontal lobe projections of serotonergic neurons are more susceptible to MDMA-related damage than are projections to other regions of the brain (Molliver 1987). Behavioural studies in humans, however, are less consistent with this interpretation. Performance on executive tasks such as Random letter generation and Tower of London provide indications of frontal lobe functioning, and while many studies have found ecstasy-related deficits on executive tasks (e.g. Fisk et al. 2004; Fox et al. 2001a; Schifano et al. 1998), outcomes often vary between studies on particular tasks (e.g. non-significant findings on Tower of London in Morgan 1998; Sobczak et al. 2002). The best interpretation of our findings may be that larger deficits are observed in tasks that require complex interactions between multiple brain regions (each of which has suffered some degree of lasting ecstasy-related change).

In future studies, it may be possible to address this question by using fMRI to directly examine the various brain regions employed across memory tasks of differing complexity and the influence of ecstasy use on these regions. One question, for example, is whether activation differences between ecstasy users and controls would be stronger in frontal regions than in 
the hippocampus or perceptual areas, when performing complex strategy-influenced memory tasks.

\section{Conclusion}

Our study of verbal memory functioning in ecstasy users has led to three major conclusions. First, verbal memory is not unitary in its susceptibility to ecstasyrelated damage: instead, behavioural deficits are stronger in complex verbal memory tasks than in simple verbal memory tasks. Second, the poor performance in complex tasks is associated with poor implementation of deliberate memory strategies. Finally, ecstasy users remain poor relative to non-drug users on complex memory tasks even after multiple learning opportunities, a finding that contrasts with improvement to normal levels in cannabis users.

Acknowledgements This study was aided by the Faculties Research Grant Scheme of The Australian National University and an Australian Post-graduate Award to John Brown. Manuscript preparation was supported by a Queen Elizabeth II Fellowship to Elinor McKone (Australian Research Council DP0450636).

\section{References}

Anglin AD, Hser Y, Chou C (1993) Reliability and validity of retrospective behavioural self-report by narcotics addicts. Eval Rev 17(1):91-108

Back-Madruga C, Boone KB, Chang L, Grob CS, Lee A, Nations H et al (2003) Neuropsychological effects of 3,4-methylenedioxymethamphetamine (MDMA or ecstasy) in recreational users. Clin Neuropsychol 17(4):446-459

Bolla KI, McCann UD, Ricaurte GA (1998) Memory impairment in abstinent MDMA ("ecstasy") users. Neurology 51(6):15321537

Brown J (2005) The pattern of memory and perceptual dysfunctions in recreational ecstasy users (unpublished thesis). Retrieved 19th Oct, 2007, from http://thesis.anu.edu.au/public/adt-ANU20060407. 155643/index.html

Brown J, Edwards M, McKone E, Ward J (2007) A long-term ecstasyrelated change in visual perception. Psychopharmacology 193 (3): $437-446$

Brunfaut E, d'Ydewalle G (1996) A comparison of implicit memory tasks in Korsakoff and alcoholic patients. Neuropsychologia 34 (12):1143-1150

Buchert R, Thomasius R, Nebeling B, Petersen K, Obrocki J, Jenicke L et al (2003) Long-term effects of "ecstasy" use on serotonin transporters of the brain investigated by PET. J Nucl Med 44 (3):375-384

Buchert R, Thomasius R, Wilke F, Petersen K, Nebeling B, Obrocki J et al (2004) A voxel-based PET investigation of the long-term effects of "ecstasy" consumption on brain serotonin transporters. Am J Psychiatr 161(7):1181-1189

Buhot MC (1997) Serotonin receptors in cognitive behaviors. Curr Opin Neurobiol 7(2):243-254

Buhot MC, Martin S, Segu L (2000) Role of serotonin in memory impairment. Ann Med 32(3):210-221
Casey PJ, Heath RA (1988) Category norms for Australians. Aust J Psychol 40(3):323-339

Cowan RL, Lyoo IK, Sung SM, Ahn KH, Kim MJ, Hwang J et al (2003) Reduced cortical gray matter density in human MDMA (ecstasy) users: a voxel-based morphometry study. Drug Alcohol Depend 72(3):225-235

Croft RJ, Mackay AJ, Mills AT, Gruzelier JG (2001) The relative contributions of ecstasy and cannabis to cognitive impairment. Psychopharmacology (Berl) 153(3):373-379

Curran HV, Morgan C (2000) Cognitive, dissociative and psychotogenic effects of ketamine in recreational users on the night of drug use and 3 days later. Addiction 95(4):575-590

Curran HV, Brignell C, Fletcher S, Middleton P, Henry J (2002) Cognitive and subjective dose-response effects of acute oral Delta(9)-tetrahydrocannabinol (THC) in infrequent cannabis users. Psychopharmacology 164(1):61-70

Daumann J Jr, Fischermann T, Heekeren K, Thron A, GouzoulisMayfrank E (2004) Neural mechanisms of working memory in ecstasy (MDMA) users who continue or discontinue ecstasy and amphetamine use: evidence from an 18-month longitudinal functional magnetic resonance imaging study. Biol Psychiatry 56(5):349-355

de Sola Llopis S, Miguelez-Pan M, Pena-Casanova J, Poudevida S, Farre M, Pacifici R et al (2008) Cognitive performance in recreational ecstasy polydrug users: a two-year follow-up study. J Psychopharmacol 22(5):498-510

de Win MM, Schilt T et al (2006) Ecstasy use and self-reported depression, impulsivity, and sensation seeking: a prospective cohort study. J Psychopharmacol 20(2):226-235

Delis DC, Kramer JH, Kaplan E, Ober BA (1987) California verbal learning test. Psychological Corporation, New York

Derogatis LR (1993) BSI: Brief Symptom Inventory: administration, scoring and procedures manual, 3rd edn. National Computer Systems, Minneapolis

Dughiero G, Schifano F, Forza G (2001) Personality dimensions and psychopathological profiles of ecstasy users. Hum Psychopharmacol 16(8):635-639

Fisk JE, Montgomery C et al (2004) Evidence for executive deficits among users of MDMA (ecstasy). Br J Psychol 95(Pt 4):457-466

Fox HC, Parrott AC, Turner JJ (2001a) Ecstasy use: cognitive deficits related to dosage rather than self-reported problematic use of the drug. J Psychopharmacol 15(4):273-281

Fox HC, Toplis AS, Turner JJ, Parrott AC (2001b) Auditory verbal learning in drug-free ecstasy polydrug users. Hum Psychopharmacol 16(8):613-618

Golding JF, Groome DH, Rycroft N, Denton Z (2007) Cognitive performance in light current users and ex-users of ecstasy (MDMA) and controls. Am J Drug Alcohol Abuse 33(2):301-307

Gouzoulis-Mayfrank E, Daumann J, Tuchtenhagen F, Pelz S, Becker $\mathrm{S}$, Kunert $\mathrm{HJ}$ et al (2000) Impaired cognitive performance in drug free users of recreational ecstasy (MDMA). J Neurol Neurosurg Psychiatry 68(6):719-725

Gouzoulis-Mayfrank E, Thimm B, Rezk M, Hensen G, Daumann J (2003) Memory impairment suggests hippocampal dysfunction in abstinent ecstasy users. Prog Neuropsychopharmacol Biol Psychiatry 27 (5):819-827

Green AR, Mechan AO, Elliott JM, O'Shea E, Colado MI (2003) The pharmacology and clinical pharmacology of 3, 4methylenedioxymethamphetamine (MDMA, “ecstasy"). Pharmacol Rev 55(3):463-508

Groth-Marnat G, Howchar H, Marsh A (2007) Memory performance in abstinent 3, 4-methylenedioxymethamphetamine (MDMA, "ecstasy") users. Percept Mot Skills 104(1):43-55

Halpern JH, Pope HG Jr, Sherwood AR, Barry S, Hudson JI, Yurgelun-Todd D (2004) Residual neuropsychological effects of illicit 3, 4-methylenedioxymethamphetamine (MDMA) in indi- 
viduals with minimal exposure to other drugs. Drug Alcohol Depend 75(2):135-147

Hatzidimitriou G, McCann UD, Ricaurte GA (1999) Altered serotonin innervation patterns in the forebrain of monkeys treated with $(+/-) 3$, 4-methylenedioxymethamphetamine seven years previously: factors influencing abnormal recovery. J Neurosci 19(12):5096-5107

Jacobsen LK, Mencl WE, Pugh KR, Skudlarski P, Krystal JH (2004) Preliminary evidence of hippocampal dysfunction in adolescent MDMA ("ecstasy") users: possible relationship to neurotoxic effects. Psychopharmacology (Berl) 173(3-4):383-390

Jasiukaitis P, Fein G (1999) Intact visual word priming in cocaine dependent subjects with and without cognitive deficit. Prog Neuropsychopharmacol Biol Psychiatry 23(6):1019-1036

Kleinbaum DG, Kupper LL, Muller KE (1988) Applied regression analysis and other multivariable methods, 2nd edn. PWS-Kent, Boston

Lezak MD, Howieson DB, Loring DW (2004) Neuropsychological assessment, 4th edn. Oxford University Press, Oxford

Lucas SK, Carstairs J, Shores EA (2003) A comparison of methods to estimate premorbid intelligence in an Australian sample: Data from the Macquarie University Neuropsychological Normative Study (MUNNS). Aust Psychol 38(3):227-237

Mandler G, Dean PJ (1969) Seriation: development of serial order in free recall. J Exp Psychol 81:207-215

McCann UD, Szabo Z, Scheffel U, Dannals RF, Ricaurte GA (1998) Positron emission tomographic evidence of toxic effect of MDMA ("ecstasy") on brain serotonin neurons in human beings. Lancet 352(9138):1433-1437

McCann UD, Szabo Z, Seckin E, Rosenblatt P, Matthews WB, Ravert HT et al (2005) Quantitative PET Studies of the Serotonin Transporter in MDMA Users and Controls Using [(11)C] McN5652 and [(11)C]DASB. Neuropsychopharmacology 30 (9):1741-1750

McCardle K, Luebbers S, Carter JD, Croft RJ, Stough C (2004) Chronic MDMA (ecstasy) use, cognition and mood. Psychopharmacology (Berl) 173(3-4):434-439

McKone E, French B (2001) In what sense is implicit memory 'episodic'? The effect of reinstating environmental context. Psychon Bull Rev 8(4):806-811

Molliver ME (1987) Serotonergic neuronal systems: what their anatomic organization tells us about function. J Clin Psychopharmacol 7 (6 Suppl):3S-23S

Montgomery C, Fisk JE, Newcombe R (2005) The nature of ecstasygroup related deficits in associative learning. Psychopharmacology (Berl) 180(1):141-149

Morgan MJ (1998) Recreational use of "ecstasy" (MDMA) is associated with elevated impulsivity. Neuropsychopharmacology 19(4):252-264

Murphy K, McKone E, Slee J (2003) Dissociations between implicit and explicit memory in children: the role of strategic processing and the knowledge base. J Exp Child Psychol 84:124-165

O'Hearn E, Battaglia G, De Souza EB, Kuhar MJ, Molliver ME (1988) Methylenedioxyamphetamine (MDA) and methylenedioxymethamphetamine (MDMA) cause selective ablation of serotonergic axon terminals in forebrain: immunocytochemical evidence for neurotoxicity. J Neurosci 8(8):2788-2803

Parrott AC, Lees A, Garnham NJ, Jones M, Wesnes K (1998) Cognitive performance in recreational users of MDMA of 'ecstasy': evidence for memory deficits. J Psychopharmacol 12(1):79-83

Posner MI, Petersen SE, Fox PT, Raichle ME (1988) Localization of cognitive operations in the human brain. Science 240(4859):16271631

Proudfoot P, Ward J (2004) ACT Party Drug Trends 2004: findings from the Party Drug Initiative (PDI). (NDARC Technical Report No. 188). National Drug and Alcohol Research Centre, University of New South Wales, Sydney
Quednow BB, Jessen F, Kühn K, Maier W, Daum I, Wagner M (2006) Memory deficits in abstinent MDMA (ecstasy) users: neuropsychological evidence of frontal dysfunction. J Psychopharmacol 20:373-384

Reneman L, Booij J, Schmand B, van den Brink W, Gunning B (2000) Memory disturbances in "ecstasy" users are correlated with an altered brain serotonin neurotransmission. Psychopharmacology 148(3):322-324

Reneman L, Lavalaye J, Schmand B, de Wolff FA, van den Brink W, den Heeten GJ et al (2001a) Cortical serotonin transporter density and verbal memory in individuals who stopped using 3, 4methylenedioxymethamphetamine (MDMA or "ecstasy") preliminary findings. Arch Gen Psychiatry 58(10):901-906

Reneman L, Majoie CB, Schmand B, van den Brink W, den Heeten GJ (2001b) Prefrontal N-acetylaspartate is strongly associated with memory performance in (abstinent) ecstasy users: preliminary report. Biol Psychiatry 50(7):550-554

Reneman L, Majoie CB, Flick H, den Heeten GJ (2002) Reduced Nacetylaspartate levels in the frontal cortex of 3, 4methylenedioxymethamphetamine (ecstasy) users: preliminary results. AJNR Am J Neuroradiol 23(2):231-237

Ricaurte GA, Martello AL, Katz JL, Martello MB (1992) Lasting effects of (+-)-3, 4-methylenedioxymethamphetamine (MDMA) on central serotonergic neurons in nonhuman primates: neurochemical observations. J Pharmacol Exp Ther 261(2):616-622

Rodgers J (2000) Cognitive performance amongst recreational users of "ecstasy". Psychopharmacology (Berl) 151(1):19-24

Roskies AL, Fiez JA, Balota DA, Raichle ME, Petersen SE (2001) Taskdependent modulation of regions in the left inferior frontal cortex during semantic processing. J Cogn Neurosci 13(6):829-843

Sabol KE, Lew R, Richards JB, Vosmer GL, Seiden LS (1996) Methylenedioxymethamphetamine-induced serotonin deficits are followed by partial recovery over a 52-week period. Part I: synaptosomal uptake and tissue concentrations. J Pharmacol Exp Ther 276(2):846-854

Savage CR, Deckersbach T et al (2001) Prefrontal regions supporting spontaneous and directed application of verbal learning strategies: evidence from PET. Brain 124(Pt 1):219-231

Scanzello CR, Hatzidimitriou G, Martello AL, Katz JL, Ricaurte GA (1993) Serotonergic recovery after (+/-)3, 4-(methylenedioxy) methamphetamine injury: observations in rats. J Pharmacol Exp Ther 264(3):1484-1491

Schacter DL, Buckner RL (1998) On the relations among priming, conscious recollection, and intentional retrieval: evidence from neuroimaging research. Neurobiol Learn Mem 70(1-2):284 303

Schacter DL, Bowers J, Booker J (1989) Intention, awareness, and implicit memory: the retrieval intentionality criterion. In: Lewandowsky S, Dunn JC, Kirsner K (eds) Implicit memory: theorectical issues. Erlbaum, Hillsdale

Schifano F, Di Furia L, Forza G, Minicuci N, Bricolo R (1998) MDMA ('ecstasy') consumption in the context of polydrug abuse: a report on 150 patients. Drug Alcohol Depend 52(1):85-90

Schilt T, Win MM, Jager G, Koeter MW, Ramsey NF, Schmand B et al (2008) Specific effects of ecstasy and other illicit drugs on 1216 cognition in poly-substance users. Psychol Med 38:13091317

Schmitter-Edgecombe M, Nissley HM (2000) Effects of divided attention on automatic and controlled components of memory after severe closed-head injury. Neuropsychology 14(4):559-569

Schott BH, Henson RN, Richardson-Klavehn A, Becker C, Thoma V, Heinze HJ et al (2005) Redefining implicit and explicit memory: the functional neuroanatomy of priming, remembering, and control of retrieval. Proc Natl Acad Sci U S A 102(4):1257-1262

Schreckenberger M, Gouzoulis-Mayfrank E, Sabri O, Arning C, Schulz $\mathrm{G}$, Tuttass $\mathrm{T}$ et al (1998) Cerebral interregional correlations of 
associative language processing: a positron emission tomography activation study using fluorine-18 fluorodeoxyglucose. Eur J Nucl Med 25(11):1511-1519

Semple DM, Ebmeier KP, Glabus MF, O'Carroll RE, Johnstone EC (1999) Reduced in vivo binding to the serotonin transporter in the cerebral cortex of MDMA ('ecstasy') users. Br J Psychiatry 175:63-69

Shaywitz BA, Pugh KR, Constable RT, Shaywitz SE, Bronen RA, Fulbright RK et al (1995) Localization of semantic processing using functional magnetic resonance imaging. Hum Brain Mapp 2:149-158

Sobczak S, Riedel WJ et al. (2002) Cognition following acute tryptophan depletion: difference between first degree relatives of bipolar disorder patients and matched healthy control volunteers. Psychol Med 32(3):503-515

Spiers HJ, Maguire EA, Burgess N (2001) Hippocampal amnesia. Neurocase 7(5):357-382

SPSS (2004) SPSS version 13.0 for windows. Chicago, SPSS Inc

Stricker JL, Brown GG, Wixted J, Baldo JV, Delis DC (2002) New semantic and serial clustering indices for the California Verbal Learning Test-Second Edition: background, rationale, and formulae. J Int Neuropsychol Soc 8(3):425-435

Thiel CM (2003) Cholinergic modulation of learning and memory in the human brain as detected with functional neuroimaging. Neurobiol Learn Mem 80(3):234-244

Thomasius R, Petersen K, Buchert R, Andresen B, Zapletalova P, Wartberg L et al (2003) Mood, cognition and serotonin transporter availability in current and former ecstasy (MDMA) users. Psychopharmacology (Berl) 167(1):85-96

Tulving E (1962) Subjective organization in free recall of "unrelated" words. Psychol Rev 69:344-354

Tulving E, Pearlstone Z (1966) Availability versus accessibility of information in memory for words. J Verbal Learn Verbal Behav 5:381-391

Wang X, Baumann MH, Xu H, Rothman RB (2004) 3, 4methylenedioxymethamphetamine (MDMA) administration to rats decreases brain tissue serotonin but not serotonin transporter protein and glial fibrillary acidic protein. Synapse 53(4):240-248

Wang J, Carlson RG, Falck RS, Siegal HA, Rahman A, Li L (2005) Respondent-driven sampling to recruit MDMA users: a methodological assessment. Drug Alcohol Depend 78(2):147-157

Ward J, Hall K, Haslam C (2006) Patterns of memory dysfunction in current and 2-year abstinent MDMA users. J Clin Exp Neuropsychol 28(3):306-324

Warrington EK, Weiskrantz L (1970) Amnesic syndrome: consolidation or retrieval? Nature 228(272):628-630

Wechsler D (1997) Wechsler Memory Scale - third edition (WMS-III). The Psychological Corporation, New York

Yip JT, Lee TM (2005) Effect of ecstasy use on neuropsychological function: a study in Hong Kong. Psychopharmacology (Berl) 179 (3):620-628

Zuckerman M (1994) Behavioral expressions and biosocial bases of sensation seeking. Cambridge University Press, Cambridge 